\title{
Assessment of Perceived Healthcare Access in a Rural Community in Rizal: A Cross-sectional Study
}

KATHYRINE A. CALONG CALONG, MA, RN https://orcid.org/0000-0002-8471-6166
JUDALYN S. COMENDADOR, MA, RN

https://orcid.org/0000-0001-5543-1420

\author{
San Beda University, Manila, Philippines \\ Corresponding author's email: kcalongcalong@sanbeda.edu.ph
}

\section{Abstract}

Background: Access to health care is considered a basic right and integral to human life. However, this still remains a challenge especially in developing countries where the majority of the poor reside and suffer from a disproportionate amount of disease. The study determined the six key components of health care access: approachability, availability, accessibility, affordability, acceptability, and accommodation, as perceived by a rural community in Taytay, Rizal, Philippines.

Methods: This descriptive-cross sectional study included a convenience sample of 62 participants. The Perceived Access to Health Care Instrument was utilized. Frequency, percentage, mean, standard deviation, and univariate linear regression were used to analyze the data.

Results: The study revealed that health care access was rated as good in terms of approachability, availability, affordability and acceptability. On the other hand, accessibility and accommodation was rated as fair. It was also revealed that none of the demographic profiles significantly predicted the perceived access to health care

Conclusion: Assessment of health care access is an important measure of health care equity and despite several factors previously shown to affect health care access, the results of this study showed that the participants have good access to health care in their community.

Keywords: Healthcare services, perceived access, rural community 


\section{Introduction}

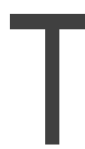

he 1946 constitution of the World Health Organization (WHO) states that "the enjoyment of the highest attainable standard of health is one of the fundamental rights of every human being without distinction of race, religion, political belief, economic or social condition. The health of all people is fundamental to the attainment of peace and security and is dependent upon the fullest cooperation of individuals and states" (p. 1). These statements magnify the link between peace and health especially with the acceptance of peace as a social determinant of health in the 1980s and the connection can be interpreted as bidirectional and dynamic in nature (Canadian Nurses Association [CNA], 2009), one cannot exist without the other. Thus, the concept of "peace through health programs" coined by Santa Barbara and MacQueen (2000), refers to "any initiative that is intended to improve the health of a population and to simultaneously heighten that population's level of peace and security."

The Universal Declaration of Human Rights (UDHR) Article 25 states that "Everyone has the right to a standard of living adequate for the health and well-being of himself and of his family, including food, clothing, housing and medical care and necessary social services...." The declaration asserts that health is an important goal of human rights and integral to the right to life (Perry, Fernandez \& Puyana, 2015). Thus, it is the responsibility of the state to provide basic health services to its citizenry without prejudice to their social status, race, religion, etc. This paved the way to the development and implementation of public health programs with the goal of improving the health of people and communities.

An individual's access to healthcare as defined by Levesque, Harris and Russell (2013) is the opportunity to identify healthcare services and to actually have a need for services fulfilled. Galama and van Kippersluis (2013) added that having access to effective healthcare is considered a fundamental component of human capital that ensures healthy living, general well-being and good quality of life. However, data from the World Health Organization (2017) revealed that at least half of the world's population cannot obtain essential health services. A report by Wan and Francisco (2009) on the access of basic services in the developing countries in Asia stated that health services fail to reach majority of the poor, who suffer from a disproportionate amount of disease. Further, Dalton and Peacock reported that poor households are five times more likely to become sick than richer households and are less likely to receive basic health services (Peters et al., 2008; Barat et al., 2004; Pillai et al., 2003). Yazbeck et al. (2005) and Wagstaff (2002) added that poor children are usually less likely to be fully immunized even in countries where national immunization programs are in place.

According to the Institute for Economics \& Peace (2018), "peaceful countries tend to ensure equity in access to resources such as education, health..." (p. 8). However, literatures have revealed that marginalized and vulnerable groups are facing challenges with access to healthcare which in turn can affect one of the eight pillars of peace which is equitable distribution of resources and 
ultimately the sustainable development goals.

In the Philippines, Filipinos suffer from dismal access to health services where eight out of ten people reported to have never undergone a medical examination (Van Gijsel, 2016). Further, the current doctor to patient ratio is $1: 33,000$ which is significantly higher than the global average of $1: 6$, 600 (Pennington, 2019). These only highlights that the delivery of basic health services remains a challenge in developing countries like the Philippines. Thus, the study was conducted to determine the perceived access to healthcare among residents in a rural area in Rizal in terms of approachability, availability, accessibility, affordability, acceptability and accommodation of healthcare services.

\section{Methods}

\section{Study Design and Sampling Technique}

The study utilized a cross-sectional research design in order to determine the perceived access to healthcare among the participants in a rural area of Rizal, Philippines. The area is situated inside a subdivision owned by a renowned real estate developer in the Philippines and the lots were donated to the local people living in the community. The said area was selected since it is the adopted community of a College of Nursing in Manila. In order to select the participants, a convenience sampling design was used and a total of 62 participants were recruited. The data were collected from November 2019 to December 2019.

\section{Participants of the Study}

The participants included community members in a rural area in Taytay, Rizal, Philippines who are 18 years old and above, male or female, have been living in the community for more than a year and agreed to participate in the study.

\section{Measurement and Instrumentation}

The study utilized the Access to Health Care (AHC) Instrument developed by Zandam, Juni, Hayati and Anisah (2017) and was translated to Filipino following the World Health Organization guidelines (WHO, n.d. as cited by Soriano \& Calong Calong, 2019). The forward translation was done by a bilingual healthcare professional while back-translation was done by another translator who is an English language teacher but has no knowledge of the instrument. Afterwards, a pretesting and cognitive debriefing was done among selected participants who met the inclusion criteria. No problems were encountered during the conduct of the interview and the intent of the questions.

The AHC instrument is a 25 -item instrument consisting of six subscales pertaining to 
approachability (6 items), availability ( 3 items), accessibility ( 3 items), affordability ( 3 items), acceptability (5 items) and accommodation (5 items) with Cronbach's alpha of $0.799,0.782,0.679$, $0.751,0.753$ and 0.752 respectively which met the criteria set by Polit and Beck (2014 as cited by Soriano \& Calong Calong, 2019). Further, the translated tool was shown to be content valid having an Item Content Validity Index (I-CVI) ranging from 0.90 to 1.0 and Scale Content Validity Index (S-CVI) of 0.94 which met the criteria set by Polit \& Beck (2006 as cited by Soriano, 2019). The survey instrument also collected demographic data on the participants, including age, sex, marital status, educational attainment, employment status, family income, and family size.

\section{Operational Definitions}

Healthcare access was defined in terms of six components including approachability, availability, accessibility, affordability, acceptability, and accommodation. Approachability is when people facing health needs are aware of certain healthcare services at hand and have an impact on the health of the individual (Levesque et al., 2013) while availability is the extent to which the supply and services are made readily available in terms of the adequacy of facilities and healthcare professionals (Levesque et al., 2013; Penchasky \& Thomas, 1981). Another aspect is accessibility which refers to the geographic location of patient to the location of facilities like perception on spatial distance and travel time to reach the facility (Obrist et al., 2007; Penchasky \& Thomas, 1981). Affordability, in turn, refers to the perception costs associated with healthcare visits such as consultation fee, travel and medical costs which can have an impact on the overall access to healthcare (Levesque et al., 2013; Peters et al., 2008). Acceptability, on the other hand, is the provision of quality services and personal treatment by healthcare providers (Peters et al., 2008; Levesque et al., 2013). Lastly, accommodation refers to the relationship between the manner in which the supply resources are organized to accept clients (including building facilities, appointment systems, hours of operation, walk-in facilities, telephone services), clients' ability to accommodate to these factors, and clients' perceptions of their appropriateness (Levesque et al., 2013; Obrist et al., 2007).

\section{Data Analysis}

The data were analyzed using frequency, percentage, mean, standard deviation. Univariate linear regression was used to determine the influence of the demographic profile on the perceived access to healthcare.

\section{Result}

The demographic profile of the participants (Table 1), revealed that the mean age was 33.4 $( \pm 13.27)$, the majority were female ( $n=39$ or $65 \%$ ), married $(n=34$ or $56.7 \%$ ) and with a high school education ( $n=35$ or $58.3 \%$ ). Further, most were employed ( $n=35$ or $56.5 \%$ ) with family income of $<$ Php19, 999 ( $n=56$ or $90.3 \%$ ) and family size of 4 to 6 members ( $n=32$ or $51.6 \%$ ). 
Table 1. Demographic Profile of the Participants $(n=62)$

\begin{tabular}{|c|c|c|c|}
\hline Characteristics & Frequency (f) & Percentage (\%) & Mean (SD) \\
\hline Age (Years) & & & $33.4( \pm 13.27)$ \\
\hline \multicolumn{4}{|l|}{ Sex } \\
\hline Male & 22 & $35.48 \%$ & \\
\hline Female & 40 & $64.52 \%$ & \\
\hline \multicolumn{4}{|l|}{ Marital Status } \\
\hline Single & 27 & $43.55 \%$ & \\
\hline Married & 35 & $56.45 \%$ & \\
\hline \multicolumn{4}{|l|}{ Education } \\
\hline Elementary Graduate & 26 & $41.9 \%$ & \\
\hline High School Graduate & 36 & $58.1 \%$ & \\
\hline \multicolumn{4}{|l|}{ Employment } \\
\hline Employed & 35 & $56.50 \%$ & \\
\hline Unemployed & 27 & $43.50 \%$ & \\
\hline \multicolumn{4}{|l|}{ Income } \\
\hline$<$ Php19, 999 & 56 & $90.30 \%$ & \\
\hline$>$ Php20, 000 & 6 & $9.70 \%$ & \\
\hline \multicolumn{4}{|l|}{ Family Size } \\
\hline 1 to 3 individuals & 23 & $37.10 \%$ & \\
\hline 4 to 6 indiivuduals & 39 & $62.90 \%$ & \\
\hline
\end{tabular}

Table 2 shows the descriptive statistics of perceived access to healthcare among the participants. The results revealed that overall, the participants had fair access to healthcare $(M=3.57$; $S D= \pm 0.35$ ). In terms of approachability, the mean score was 3.81 which can be interpreted as good, whereas the mean score for availability was 3.47 which can be interpreted as good. The accessibility was rated as fair $(M=3.48)$ and the affordability was rated as good $(M=3.75)$, Furthermore, the mean score of acceptability was 3.45 which can be interpreted as good while accommodation was rated as fair $(M=3.35)$.

Table 2. Descriptive Statistics of Perceived Access to Health Care $(n=62)$

\begin{tabular}{lrrrr} 
& Mean & Standard Deviation & \multicolumn{2}{c}{ Interpretation $^{\text {a }}$} \\
\hline Perceived Access to Health Care & 3.57 & $\mathbf{0 . 3 5}$ & \multicolumn{2}{c}{ Good } \\
Approachability & & & \pm 0.54 & Good \\
Availability & 3.81 & \pm 0.57 & Good \\
Accessibility & 3.47 & \pm 0.68 & Fair \\
Affordability & 3.48 & \pm 0.58 & Good
\end{tabular}




\begin{tabular}{lrrrr} 
& Mean & Standard Deviation & Interpretationa \\
\hline Acceptability & 3.45 & \pm 0.47 & Good \\
Accommodation & 3.35 & \pm 0.56 & Fair \\
\hline aLegend: & Very Poor $=1.00$ to 1.79 & & Poor $=1.80$ to 2.59 & \\
& Fair $=2.60$ to 3.39 & & Good $=3.40$ to 4.19 & \\
& Excellent $=4.20$ to 5.00 & \\
\hline
\end{tabular}

The results of the univariate linear regression analysis of the influence of the demographic characteristics on perceived access to healthcare of the participants is depicted in Table 3. None of the demographic characteristics significantly predicted perceived access to healthcare.

Table 3. Univariate linear regression of perceive access to healthcare $(n=62)$

\begin{tabular}{cccccc}
\hline & Source & $\begin{array}{c}\text { Regression } \\
\text { Coefficient }\end{array}$ & SE B & p value & R squared \\
\hline & Age & 0.004 & 0.169 & 0.581 & 0.016 \\
& Sex & -0.004 & 0.136 & 0.975 & 0.000 \\
Perceived Access to & Civil Status & 0.040 & 0.120 & 0.740 & 0.002 \\
Health Care & Education & -0.169 & 0.132 & 0.207 & 0.026 \\
& Employment & 0.030 & 0.135 & 0.219 & 0.001 \\
& Income & 0.060 & 0.227 & 0.794 & 0.001 \\
& Family Size & -0.201 & 0.136 & 0.146 & 0.035 \\
\hline
\end{tabular}

Regression equation: $\quad Y^{\prime}=4.30+0.004-0.004+0.040-0.169 \_0.030+0.060-0.201$

\section{Discussion}

The study was conducted in order to assess perceived access in healthcare among residents of a rural area in Rizal, Philippines. The findings revealed that there was a good approachability of healthcare access; meaning that the participants are well aware of the healthcare services in the community. This is likely attributed to the community being one of the adopted communities of a university in Manila. As an adopted community, they received healthcare services and outreach programs as well as information drives which is conducted in partnership with the local government. This may also be the reason why the participants rated availability of healthcare as good. Asasira and Ahimbisibwe (2018) stated that partnership arrangement between public and private organizations will enable adequate delivery of healthcare services to the clients.

The influence of geography has been shown to affect access to healthcare (Arcury et al., 2005); healthcare facilities that are 30 minutes within the community are considered as accessible (Famorca, Nies, \& McEwen, 2013). It can be noted that the accessibility of healthcare was rated by the participants as fair. This means that distance from the health facility did not pose a problem and 
that the health facility was within a reasonable distance from the catchment population it was intended to serve.

In terms of affordability, the literature has revealed that poor people with lower level of education would perceive access to healthcare to be more challenging than those with higher education and higher income (Borders, Aday \& Xu, 2004; Moss, 2000). However, this was not the case in this study; since monthly income and education were not shown to be predictors of perceived access. It was interesting to note that the affordability of healthcare services was rated by the community as good, since ensuring the affordability of healthcare remains an important factor in achieving access to high-quality healthcare (Agency for Healthcare Research and Quality, 2017).

The participants of the study rated acceptability of healthcare services as good. Acceptability is essential since it encompasses patient satisfaction with the care received. Studies have shown that patients who are satisfied with quality of care are more likely to continue with care, adhere to medical instructions, and are also unlikely to patronize non-professional medical practitioners (Pascoe, 1983; Vuori, 1987).

Accommodation, on the other hand was rated by the participants as fair, suggesting that the structures and facilities present in the healthcare facilities were successfully accommodating the number of people in the community.

Overall, the participants have revealed a good access in healthcare services. This finding can be attributed to the implementation of Universal Health Care Program by the Aquino government in 2016. This program was developed with the goal of providing equitable access to affordable and quality health services thereby addressing inequity in healthcare system.

The study had the following limitations: (1) although there are supply-side features of the health system and organization and demand side features of populations (Levesque et al., 2013), the study only explored the supply side without attempting to assess the demand side of the population, (2) a convenience sample was used, hence, generalizability of the results is limited, (3) lastly, the study only focuses on the perception of healthcare access without attempting to measure the healthcare seeking behaviors and healthcare utilization of the participants.

\section{Conclusion}

Assessment of health care access is an important measure of health care equity and despite several factors previously shown to affect health care access. Results of this study showed that the participants have a good access to health care in their community. 


\section{Funding}

This study is funded by San Beda University through its Research and Development Center, AY 2019-2020 Research Grants.

\section{References}

Agency for Healthcare Research and Quality (2017). 2016 National Healthcare Quality and Disparities Report. Retrieved from: https://www.ahrq.gov/research/findings/nhqrdr/nhqdr16/quality.html

Arcury, T., Gesler, W., Preisser, J., Spencer, J., \& Perin, J. (2005). The Effects of Geography and Spatial Behavior on Health Care Utilization among the Residents of a Rural Region. Health Services Research, 40(1), 135-156. doi: 10.1111/j.1475-6773.2005.00346.x

Asasira, J. \& Ahimbiisbwe, F. (2018). Public-Private Partnership in Health Care and Its Impact on Health Outcomes: Evidence from Ruharo Mission Hospital in Uganda. International Journal of Social Science Studies, 6(20), 79-87. doi: 10.11114/ijsss.v6i12.3911

Barat, L. M., Palmer, N., Basu, S., Worrall, E., Hanson, K., \& Mills, A. (2004). Do Malaria Control Interventions Reach the Poor? A View Through the Equity Lens. The American Journal of Tropical Medicine and Hygiene, 71(2), 174-178.

Borders, T. F., Aday, L. A., \& Xu, K. T. (2004). Factors Associated With Health-Related Quality of Life Among an Older Population in a Largely Rural Western Region. The Journal of Rural Health, 20(1), 67-75. doi 10.1111/j.1748-0361.2004.tb00009.x

Canadian Nurses Association (2009). FactSheet: Peace and Health. Retrieved from: https://www.cnaaiic.ca/ /media/cna/page-content/pdf-fr/fs27_peace_health_2009_e.pdf? la=en

Famorca, Z., Nies, M., \& McEwen, M. (2013). Nursing Care of the Community. Singapore: Elsevier Saunders

Galama, T. J., \& van Kippersluis, H. (2013). Health Inequalities through the Lens of Health Capital Theory: Issues, Solutions, and Future Directions. Research on Economic Inequality. 21, 263-284. doi: 10.1108/S1049-2585(2013)0000021013

Institute for Economics \& Peace. (2018) Positive Peace Report 2018: Analysing the factors that Sustain Peace. Retrieved from: http://visionofhumanity.org/reports

Levesque, J. F., Harris, M. F., \& Russell, G. (2013). Patient-centered access to healthcare: conceptualizing access at the interface of health systems and populations. International Journal for Equity in Health, 12, 18. doi: 10.1186/1475-9276-12-18

Moss, N. (2000). Socioeconomic disparities in health in the US: an agenda for action. Social Science \& Medicine, 51(11), 1627-1638. doi: 10.1016/S0277-9536(00)00058-7

Obrist, B., Iteba, N., Lengeler, C., Makemba, A., Mshana, C., Nathan, R., ... Mshinda, H. (2007). Access to health care in contexts of livelihood insecurity: a framework for analysis and action. PLoS Medicine, 4(10), 1584-8. doi: 10.1371/journal.pmed.0040308

Pascoe, G. (1983). Patient satisfaction in primary health care: a literature review and analysis. Evaluation and Program Planning. 6(3):185-210

Penchansky, R., \& Thomas, J. W. (1981). The concept of access: definition and relationship to consumer satisfaction. Medical Care, 19(2), 127-40. Retrieved from http://www.ncbi.nlm.nih.gov/pubmed/7206846 
Pennington, J. (2019). Healthcare for all in the Philippines - but is there a catch? Retrieved from: https://www.aseantoday.com/2019/02/healthcare-for-all-in-the-philippines-but-is-there-a-catch/

Perry, D., Fernadez, C., \& Puyana, D. (2015). The Right to Life in Peace: An Essential Condition for Realizing the Right to Health. Health and Human Rights Journal, 17(1)

Peters, D. H., Garg, A., Bloom, G., Walker, D. G., Brieger, W. R., \& Rahman, M. H. (2008). Poverty and access to health care in developing countries. Annals of the New York Academy of Sciences, 1136, 161-171. doi: 10.1196/annals.1425.011

Pillai, R. K., Williams, S. V., Glick, H. A., Polsky, D., Berlin, J. A., \& Lowe, R. A. (2003). Factors Affecting Decisions to Seek Treatment for Sick Children in Kerala, India. Social Science \& Medicine. 57(5), 783-790.

Santa Barbara, J. \& MacQueen, G. (2004). Peace through health: key concepts. Lancet. 364, 384-386.

Soriano, G. P. \& Calong Calong, K. A. (2019). Psychometric Evaluation of Filipino Version of Patient

Satisfaction Instrument. Belitung Nursing Journal, 5 (6), 251-256. doi: 10.33546/bnj.867

Soriano, G. \& Calong Calong, K. (2019). Construct Validity and Reliability of Caring Nurse Patient Interaction

Scale-Nurse among Filipino Nurses. International Journal of Caring Sciences, 12(2), 1017-1022

Soriano, G. (2019). Psychometric Evaluation of the Filipino Version of Caring Nurse Patient Interaction Scale Patient. International Journal for Human Caring, 23(4), 329-333. doi: 10.20467/1091-5710.23.4.329

Universal Declaration of Human Rights. (1948). Art. 25. Retrieved from: https://www.un.org len/udhrbook/pdf/udhr_booklet_en_web.pdf

Van Gijsel, N. (2016). Health Care Access in the Philippines. Third World Health Aid. Retrieved from: https://en.vivasalud.be/sites/default/files/generated/files/news/positionpaper_gezondheid_philippine S_eng_0.pdf

Vuori, H. (1987). Patient satisfaction--an attribute or indicator of the quality of care? QRB Quality Review Bulletin.13(3):106-8.

Wagstaff, A. (2002). Poverty and Health Sector Inequalities. Bulletin of the World Health Organization. 80(2), 97-105

Wan, G., \& Francisco, R. (2009). Why is Access to Basic Services Not Inclusive? A Synthesis with a Special Focus on Developing Asia. ADB Sustainable Development Working Paper Series. Mandaluyong, Metro Manila: Asian Development Bank

World Health Organization (2017). Half the world lacks access to essential health services, 100 million still pushed into extreme poverty because of health expenses. Retrieved from: https://www.who.int/newsroom/detail/13-12-2017-world-bank-and-who-half-the-world-lacks-access-to-essential-health services-100-million-still-pushed-into-extreme-poverty-because-of-health-expenses

Yazbeck, A.S., Gwatkin, D. Wagstaff, A., \& Qamruddin, J. (2005). Reaching the Poor with Health Nutrition, and Population Services: What Works, What Doesn't and Why. Washington, DC: World Bank.

Zandam, H., Juni, M. Hayati, K., Anisah, B. (2017). Development and Validation of Perceived Access to Health Care Measurement Instrument. International Journal of Public Health and Clinical Sciences, 4(5), 158-171 
Kathyrine A. Calong Calong, MA, RN is a graduate of Bachelor of Science in Nursing from the Metropolitan Medical Center-College of Arts, Science and Technology and received her Master of Arts in Nursing Degree Major in Leadership and Management from Centro Escolar University. She has worked as a staff nurse in several institutions including Metropolitan Medical Center and Manila Medical Center. Currently, she is the Level 1 Coordinator of San Beda University-College of Nursing. Her master's research is focused on the caring behaviors among nurses working in Level 3 hospitals. She is pursuing her Doctor of Philosophy in Nursing Education at St. Paul University of the Philippines Manila. She is a member of the Philippines Nurses Association and Philippine Nursing Research Society.

Judalyn S. Comendador, MA, RN is an experienced nurse clinician in emergency nursing and major disaster response locally and abroad. She is also a nurse educator and had taught in top universities in the Philippines. She is one of the pioneer leaders in nursing education and staff development in military hospitals abroad. With skillful knowledge in competency-based assessment and experience in multicultural nursing leadership and management. She is currently working in San Beda University as Skills Laboratory Manager, Lecturer, and Clinical Instructor. 